\title{
1 Gender, intersectionality and institutions
}

\author{
Annica Kronsell and \\ Gunnhildur Lily Magnusdottir
}

\section{Introduction}

Climate change is one of the main security challenges of the 21st century and a growing concern among the public, politicians and civil societies around the globe. Climate objectives that have been agreed upon globally and nationally require substantial changes in most societal sectors and call for broad societal engagement. Proposed strategies tend to focus on technical and economic solutions, while research stresses the importance of social inclusion to achieve a climate transition in line with current sustainability goals. Political and administrative institutions at different levels, i.e. international organisations, the EU Commission and its directorates, national, regional, as well as municipal governments and administrations, are authoritative key actors in climate policy-making. However, there are often shortcomings in their climate policy-making, most prominently their prevalent focus on technical innovations and economic incentives, and the lack of attention to social dimensions. There are important social differences that deserve recognition and this book will address this lack by providing gender and intersectional perspectives on climate policy and institutions.

Research shows how greenhouse gas emissions, vulnerability to impacts and political participation vary considerably across the population, according to gender, race, class, age, geography and other intersectional factors (IPCC, 2014; Kaijser and Kronsell, 2014; Djoudi et al., 2016; Alber et al., 2017; Buckingham and Le Masson, 2017, pp. 3-5). Recognition of social differences needs to inform climate policy and the incorporation of the UN's Sustainable Development Goals provides an impetus. If social differences are left unattended to, climate policy will likely reinforce existing inequalities, but it will also risk overlooking differential effects and ending up becoming ineffective and give rise to protests among groups who feel unjustifiably challenged by climate policies and decisions.

Research on climate institutions in industrialised states - in the Global North - indicates a lack of knowledge among policy-makers on social differences and how to include climate-relevant social factors into climate objectives, such as in governmental agencies in Scandinavian countries and in the EU Commission's Climate Action Directorate (Allwood, 2014; Magnusdottir and Kronsell, 2015, 2016; Buckingham and Le Masson, 2017). There is clearly a need for more 


\section{Kronsell and Magnusdottir}

knowledge on how social equity, equality and justice issues are and can be included in climate policy-making. In turn, this requires more knowledge about how social differences are relevant to the policy fields that are most significant for realising climate objectives, going beyond the environmental sector to include transport, energy, industry, building, land use and waste, sectors where activities that lead to carbon emissions are carried out. Thus, climate institutions in industrialised states are the primary focus of the book. Climate institutions can be narrowly defined as governing bodies at different levels, such as global and regional intergovernmental organisations as well as state and local authorities. Inspired by institutionalist scholarship, the concept institution does not merely refer to formal aspects but includes the people, i.e. climate policy-makers and, most importantly, we include the norms, rules and practices of the governing climate bodies in our definition of climate institutions (March and Olsen, 1989; Mackay et al., 2010).

Gender analysis, developed from feminist theory, is the theoretical starting point of the book but an intersectional approach increases our understanding 'that there are different ways in which different women and men are affected by and relate to climate change, mediated by power structures which they experience differently' (Buckingham and LeMasson, 2017, p. 5). Intersectionality has been recognised in the broader feminist environmental literature as a useful tool to analyse 'capitalism, rationalist science, colonialism, racism, (hetero) sexism and speciesism' (MacGregor, 2017, pp. 1-2). Feminist intersectional research on climate change has to a large extent focused on developing states, and on the violence of climate events, storms, hurricanes, fires and on gendered vulnerabilities of such climate change events (Kinnvall and Rydstrom, 2019). While such research is relevant and highlights the serious effects of climate change, our work zooms in on industrialised states and on how their formal and informal climate institutions shape and develop their climate strategies. For one, this is because the industrialised countries need to reduce their carbon emissions drastically and do so with increasing urgency (UNFCCC, 2015). Second, climate policies developed in rich industrialised countries tend to become normative for other countries that then follow suit (Sommerer and Lim, 2016; Griffin Cohen, 2017; Tobin, 2017). Third, rich industrialised countries, e.g., in Europe and North America, are interesting since they have developed welfare systems and the resources needed to become green decarbonised states (Duit et al., 2016). Moreover, as shown in previous studies, equality and social issues, the diversity of the public and their various needs and behavioural patterns, such as transport behaviour of different groups, have not been sufficiently recognised by industrialised states (Allwood, 2014; Magnusdottir and Kronsell, 2015, 2016; Alber et al., 2017; Buckingham and Kulcur, 2017).

Accordingly, the overall aim of the book is to explore if and how climate institutions in industrialised states work with recognition and understanding of social differences in climate policy-making. We argue that the focus on climate institutions is important since they not only develop strategies and policies, but they also produce power relations, for example, by distributing resources such as through strategies for a green economy. Climate institutions also affect power 
relations by promoting specific norms and values such as ecological modernisation and by including specific types of knowledge only, for example by privileging technical knowledge. The different chapters of this book investigate policy-making in climate institutions and the role of informal institutions and norms, from the perspective of power related to gender and other intersecting social factors. We start by discussing the international institution of the United Nations Framework Convention on Climate Change (UNFCCC), because its norms established through international negotiations are significant as part of the norms that guide policies. All the institutions discussed in this book adhere and relate to the UNFCCC regime (see further in chapter two, this volume). The regime has become normative at national, as well as local levels, and in different sectors in many industrialised states. The existence of climate norms at multiple levels and within different governmental or sector institutions, is evident in chapters both focusing on intergovernmental organisations, such as the UN and the EU as well as state and local authorities. As we are highly concerned with what the enactment of relevant norms like climate emission targets imply for gender equality, equity and justice, we investigate several different institutions where the actions required from climate agreements take place. In studying these and other relevant institutions the book explores and addresses the following two important questions:

What are the main institutional challenges and barriers to the inclusion of climate relevant social factors and in particular gender in climate policy-making?

What and where are the main opportunities to advance gender equality, equity and social justice within climate institutions?

Our main ambition is to study climate institutions, which makes feminist institutional theory a particularly relevant frame. Below we outline how institutional approaches combined with gender and intersectional perspectives can contribute to further an understanding of power relations within climate institutions in industrialised states and thereby highlight the challenges and opportunities for advancing gender equality, equity and social justice.

\section{Representation in climate policy-making}

How gender and other social categories are represented in climate institutions is important for discussions of inclusive climate strategies. If gender representation is imbalanced in climate authorities it can be a sign of an ill-functioning democracy or a democratic deficit, preventing the development of inclusive and gendered climate policies. Drawing on Anne Philip's (1995) politics of presence, two main categories of representation have been developed, descriptive and substantive redundant (Lovenduski, 2005; Chaney, 2012). Descriptive representation relates to the number of women and men who can influence policy-making, that is, the relationship and balance between males and females in political institutions 


\section{Kronsell and Magnusdottir}

(Wängnerud, 2009, p. 53). When women are represented in greater numbers it is often the result of formal or informal quotas (Dahlerup and Leyenaar, 2013). Gender equity guidelines aim for a balance between male and female bodies, falling within the 40-60\% range and qualify descriptive representation with the argument that the presence of only a few women in politics will not make a real difference (Lovenduski, 2005). Instead, it is argued that a certain number of women, a critical mass, must be present in order for their actions to produce substantial effects (Dahlerup, 1988, 2006). Concepts like critical mass and mechanisms involving gender quotas have helped to establish a growing female presence in politics and policy-making but can be problematic when reduced to mere numbers. Based on a democratic ethos as the baseline, representation should be inclusive and reflect the citizenry. Here, we broaden the perspective to include other climate-relevant social categories that intersect with gender, when analysing what kind of knowledge is included or excluded, and which voices are represented in the policy-making process.

Feminists have argued that rather than looking at numbers, it is critical acts - action that makes a difference - that matters. This is tricky as it is linked to the question of whether women will make a difference or not, once they have been included in the polity and often there is an idea that they will, although this is seldom explicit (Dahlerup, 2006; Mushaben, 2012). Normally, it is based on some vague idea of a certain difference between men and women acquired through diverse life experiences and conditions, hence, leading to expectations that they bring into policy, diverse interests, knowledge and perspectives. When we move beyond the gender binary and include other social categories in the discussion about substantive representation, the idea of what additional qualities the experiences of these groups will bring to institutions becomes even more complicated. Hence, we suggest that it suffices to argue for social inclusion on the basis of democratic rights and social justice. The degree of representation for women and other social groups will remain a pertinent issue also for the chapters in this book, not least due to the rather extreme conditions of male dominance exemplified in the different sectors, i.e. transport, energy, building or the 'green economy', which are taking on climate mitigation challenges.

Beyond this, we are mostly interested in critical climate acts. What are some of those critical acts that policy-makers and civil servants can perform in order to elicit change? Gender mainstreaming is a strategy endorsed in the EU (since 1996) and by many institutions of its member states, which pushes the work with gender issues beyond adding women. It rests on the idea that most activities have a gender dimension found in the underlying norms of institutions (Woodward, 2003; Kantola, 2010; Lowndes, 2020). The strategy is to 'mainstream' women's experiences and needs by incorporating gender perspectives into all policy areas, at all stages, at all levels. Gender experts are often assigned the task of gender mainstreaming (Ferguson, 2015; Bustelo et al., 2016). Gender experts and advisors have a particular role in the institutions and are assumed to have specific knowledge of gender relations. They may perform critical acts. The concept femocrats, captures the more transformational aspect of such critical acts as it names 
feminist civil servants, inspired by feminist movements, who work to further gender and feminist concerns within government and administrative institutions (Eisenstein, 1996; Yeatman, 2020). Similarly, green activists within administrations perform in the same way on the basis of their dedication to environmental concerns (Hysing and Olsson, 2017). A related concept is that of 'outsiders within' originally from black feminist theory. Patricia Hill Collins (1986) points to the importance of individual actors in policy development and how they can bring in new and alternative perspective and knowledge on, for example, gender and race to climate policy-making from their positions as 'others'. These questions about if and how an increased number of female policy-makers in climate institutions and in climate-relevant sectors matters are addressed in various chapters.

\section{Path dependence in climate institutions}

Feminist institutionalism argues that it is important for feminist scholars to study institutions because they organise power inequalities through formal as well as informal rules and practices (Mackay et al., 2010; Krook and Mackay, 2011; Ljungholm, 2017; Miller, 2020). Through historical processes, power inequalities become deeply embedded in organisations and are reinforced over time and the resulting institutional arrangements then steer or guide political actions (Pierson, 2004, p. 11). Institutions tend to have particular 'pattern-bound' effects over time, caused by locking into place certain rules and norms of behaviour which also give institutions resilience (Krook and Mackay, 2011; Waylen, 2014; Lowndes, 2020). This explains why historically derived notions of gender tend to persist. Path dependence makes institutions 'sticky' and opportunities for innovation and change are thereby constrained by previous choices (Kenny, 2007, p. 93; Miller, 2020). In line with this historical institutional perspective, climate institutions can be viewed as path-dependent when it comes to both gender recognition and the acknowledgement of other intersecting social factors such as class, ethnicity, age, location and education. The stickiness or path dependence of climate institutions that have significance here is related to how climate change was originally put on the global agenda as a highly scientific, elitist, technical and masculinised issue, privileging mainly the natural science community to define the problem, thus downplaying and making irrelevant social interpretations (Skutsch, 2000; Hemmati and Röhr, 2009). In their study of the Commission Directorate-General for Climate Action, Magnusdottir and Kronsell (2016) concluded that the existing power order was reproduced within a new institutional environment -in the then newly established DG Climate Action of the Commission - where path dependence meant that policy-makers in DG Climate Action largely accepted and adapted to the established masculinised institutional environment in which EU climate policies were formulated.

Path dependence often has to do with normalisation, for example of masculinity and of gender binaries. Normalisation reproduces power through simple everyday acts that are perceived as normal and it does not require overt struggles (Kronsell, 2016). From the lens of feminist institutionalism, institutional 


\section{Kronsell and Magnusdottir}

practices are based on a logic that may make the inclusion of gender and other intersecting social factors appear less appropriate and less desirable. It builds on March and Olsen's (1989, pp. 21-38, p. 161) ideas about how institutions are reproduced through patterns of action in a 'logic of appropriateness'. The logic is that individual policy-makers follow embedded rules and routines, according to what is appropriate for their social and professional role and individual identity. Feminist institutionalists coined the more specific 'gendered logic of appropriateness', which: 'prescribes (as well as proscribes) acceptable masculine and feminine forms of behaviour, rules and values for men and women within institutions' (Chappell and Waylen, 2013, p. 601). Accordingly, it is not the individual interest or personality of political actors in climate institutions that is important but how individuals give their actions meaning. What will be considered appropriate in any given situation is not trivial. 'Actions are fitted to situations by their appropriateness within a conception of identity' (March and Olsen, 1989, p. 38). The outcomes of these institutional practices, thus the actual climate actions, policies and the included parameters, aspects, issues and knowledge, depend on the role expectations of individual policy-makers and how they make their role meaningful. If climate policy-making is taking place in the energy, environment or transport agencies, as is the case in most industrial states, then the rules and culture of those institutions as well as the professional identity of the policymakers, perhaps educated as engineers or economists, are likely to affect whether and how they view social power relations in policy-making. Within engineering, technical solutions may seem most appropriate while economists may focus on societal costs. Several chapters in this book critically assess climate policy-making from the feminist institutional perspective. They reveal path dependencies, while at the same time remaining open to the possibility of change, in search of transformations that challenge the 'stickiness' of climate institutions. Thus, the book raises questions about how climate policy-makers are affected by this stickiness and bound by a gendered logic of appropriateness and if or how institutional path dependence can be challenged.

\section{Intersectionality as a tool in institutional analysis}

Intersectionality was developed in feminist theory as a way to complicate the analysis of gender, arguing that gender is hardly ever a power relation that stands alone, but is related to other power differences, such as class, ethnicity and age (Davis, 2008). Intersectionality is an important concept and an analytical tool that can shed light on how power structures around social differences emerge and interact (see e.g., Lykke, 2010; Cho et al., 2013; Buckingham and Le Masson, 2017). Surely, it is applicable to climate issues. While gender is highly relevant (Alston, 2013; Resurrección, 2013), it is also nested into other power categories, for example, depending on context and place (Nagel, 2012; Kaiser and Kronsell, 2014) and related to economic status, e.g., in explaining carbon emissions (Ergas and York, 2012; MacGregor, 2017, p. 22) and ecological footprints. Although our starting point is in exploring gender difference, many of the chapters in this book reflect 
on which social categories are recognised and conceptualised in policy-making and ask questions about whether intersectional aspects are visible and/or included.

The contributions to this book are placed in three interconnected thematic parts, which focus on climate institutions, both formal authorities and informal, normative institutions, in industrialised states.

\section{Part 1: Intergovernmental and governmental climate institutions}

The first part of the book outlines the broader scene of climate policy-making with its focus on formal intergovernmental and governmental climate institutions and how they work - e.g. with recognition of gender and other intersectional factors, gender representation, and gender equality in climate policy-making. The chapters in this part discuss the importance of formal institutions as well as the role of individual civil servants who might be dictated by a gendered logic of appropriateness. The chapters in Part 1 highlight the importance of representation in policy-making and the effects of path dependence as well as how formal institutions shape power relations and produce knowledge and norms in climate policy-making.

In Chapter 2, 'Gender in the global climate governance regime: a day late and a dollar short?', Karen Morrow outlines the evolution of gender representation in the global climate governance regime (the UNFCCC), which is important for furthering international cooperation and for its prominent influence on climate agendas across the world. The UNFCCC's tardiness to act on gender is puzzling, not the least in comparison to activities within other Rio conventions. Although a laggard on gender, Morrow reflects on the efforts made since its belatedly official recognition to the Gender Constituency in 2011. She discusses impediments to this process of improvements, which is conditioned by systemic features of the UNFCCC regime in international law and politics and an economics-driven, technocratic stance on climate issues. Such path dependencies influence both the treatment of gender and broader social inclusion and thus, also the efficacy of initiatives taken so far.

In Chapter 3 on the EU external climate policy, Gill Allwood notes that EU is committed to gender equality - a fundamental value in most policy areas, including EU's external relations - but EU climate policy is still largely gender-blind. It is the strong impact and vulnerability to climate change in countries outside Europe, that has provided a powerful framing of climate change as a development issue and where it has related to gender concerns. In turn, this framing has served the interest of a security-focused foreign policy which downplays any efforts to mainstream gender or prioritise social inclusion. The chapter stresses the importance of issue framing resulting in an institutional stickiness that opens for certain actors to engage and excludes others. This trajectory means that the gender agenda and the climate agenda remain separate tracks although they are both embedded in the EU's legal framework and institutions.

In Chapter 4, 'Making Germany's climate change policy gender-responsive', Gotelind Alber, Diana Hummel, Ulrike Röhr and Immanuel Stieß, highlight 


\section{Kronsell and Magnusdottir}

how German climate institutions have worked with gender, intersectionality and civil society. German climate policy-makers have only recently begun addressing gender and have primarily been inspired by international agreements such as the UNFCCC Gender Action Plan. Recognising that research on these issues was lacking, the authors engaged in a research project which developed a Gender Impact Assessment tool as an instrument to analyse gender equality which was made available to policy-makers. The chapter accounts for these experiences and also sheds light on critical acts or the efforts made by the (female) minister for the environment to motivate and educate senior staff and climate change experts on gender and climate policy and how cooperation with female leaders in environmental organisations was key for gender to gain traction in German climate policy-making.

In Chapter 5, 'Promoting a Gender Agenda in Climate and Sustainable Development, Gerd Johnsson-Latham and Annica Kronsell offer valuable insights into the institutional challenges government officials face when initiating an inclusive gender-equal approach. The view is from 40 years of experience as a 'femocrat' working within the Swedish government, the Ministry of Foreign Affairs and in international institutions. The chapter emerged as a dialogue between a feminist academic and a feminist bureaucrat and the resulting narrative is analysed against reflections from feminist institutional theory. It offers an insider's perspective of institutional practices by highlighting the institutional challenges that government officials face when promoting gender equality in sustainability and climate issues and how they navigate that space in order to gender mainstream the agenda, e.g. through several different types of critical acts elaborated in the text.

In Chapter 6, 'Take a ride into the danger zone? Assessing path dependency and the possibilities for instituting change at two Swedish government agencies', Ben Singleton and Gunnhildur Lily Magnusdottir argue that government agencies are important sites for climate change action. Yet, the action space available to civil servants reflects historically embedded norms in those institutions, i.e., path dependencies that relate to the prevalence of ecological modernisation and the preference for technical solutions. This frames subsequent policies with direct consequences for what type of climate action is possible. Using interview data, it explores how Swedish civil servants frame possibilities for institutional action and change on social justice in climate action. The civil servant is positioned in an ambiguous space, acting according to the logic of appropriateness in the context of the general ethos of bureaucracy within the specific logic of the agency's remit. On the other hand, in line with another task of public officers to act and serve the will of the democratically elected government transmitted from the political level.

\section{Part 2: Sectoral climate institutions}

The second thematic part of the book discusses how different climate-relevant sectoral institutions in transport, energy, construction and the green economy 
work with the inclusion of gender and other intersecting social factors. These chapters discuss the challenges and barriers related to path-dependent norms and how they can be challenged, and address questions on how an increased number of female policy-makers and/or professionals have a bearing on climate institutions and in climate-relevant sectors.

In Chapter 7, 'Towards a climate-friendly turn? Gender, culture and performativity in Danish transport policy', Hilda Rømer Christensen and Michala Hvidt Breengaard stress that configurations of environmentally friendly transport and gender are vital in policy-making. The authors demonstrate how such alignments have unfolded in Denmark by examining a range of communicative events related to gender and the enhancement of more climate-friendly transport practices. Using digital media archives and drawing on recent network analysis of the Danish political elite, they disclose how the car-centred society has been constantly re-constituted and maintained in both societies and the particular culture of transport policy. Further, they expose an institutional path dependence around car-centrism and masculine dominance that reconstitutes existing norms in transport policy-making and culture. Through the analysis, both the potentials and limitations of change are considered. It demonstrates how the longstanding alliances of car culture and hegemonic masculine norms were performed at a critical moment in the development of Danish transport policy. It locates the gendered and cross political character of the alliances and hegemonies implicated in policymaking and shows how various femininities and masculinities have been shaped and nurtured within these institutional and hegemonic structures and cultures.

In Chapter 8, 'Wasting resources: challenges to implementing existing policies and tools for gender equality and sensitivity in climate change-related policy', Susan Buckingham explores how waste management can make a significant contribution to curbing greenhouse gas emissions across Europe. However, given waste management's record as being historically male-dominated, engineeringfocused and having deeply embedded masculinist structures and path dependencies, it is not clear that it is yet up to the task. The author's involvement in two research projects exploring the relationship between gender equality and waste minimisation provides a unique experience from which she reflects on the capacity for, and challenges to, gender mainstreaming in waste management, and its associated environmental benefits. The chapter sets this exploration within the broader context of gender mainstreaming in the EU and explains how commitment to and awareness of gender equality and sensitivity vary widely depending on prior engagement with gender equality.

In Chapter 9, 'Gender analysis of policy-making in construction and transportation', Bipasha Baruah and Sandra Biskupski-Mujanovic focus on two sectors (construction and transportation) deemed critical to Canada's green economy, though sectors in which women are severely underrepresented. Using a gender equality perspective, they analyse existing government policies and programmes as well as corporate and civil society initiatives. Taking a starting point in Anne Phillip's work (1995), they emphasise the importance of promoting employment equity measures in these sectors where women are marginalised. They discuss 
institutionalised challenges that women face in these 'masculine sectors' and explore the role of different actors, including the limited role of the federal government, in framing and implementing effective policies to enable the transition to a green economy.

Chapter 10, 'Why radical transformation is necessary for gender equality and a zero carbon European construction sector', reveals how gendered analysis can help identify structural problems, in this case for the construction sector. Linda Clarke and Melahat Sahin-Dikmen argue that these structural problems need to be solved for a climate transition and gender equality to be accomplished, and in tandem, because they are interdependent. The context of their study is the European Union's (EU) strategy to reduce environmental carbon emissions in building construction - which of considerable importance as the construction industry is responsible for $30-40 \%$ of end-use emissions in EU. As a heavily white, male-dominated industry, the representation and participation of women across the construction sector are very low and the industry remains (gender) blind to this fact. Also, this sector works under the path dependence of ecological modernisation and is technology-driven.

\section{Part 3: Local, community institutions and climate practices}

The third theme explores normative climate institutions and community authorities in local policy-making. The chapters reflect on which social categories are conceptualised and recognised in policy-making and ask questions about whether and how intersectional aspects are visible and/or included. They also raise questions about how climate policy-makers are affected by path dependence and gendered logic of appropriateness and if or how institutional path dependence - e.g., existing norms on ecomodern masculinity - can be challenged.

In Chapter 11, 'Addressing climate policy-making and gender in transport plans and strategies', Tanu Priya Uteng, Marianne Knapskog, André Uteng and Jomar Sæterøy Maridal argue for the need to recognise gendered daily mobilities in developing climate policies due to the way gender/intersectionality is linked to transport patterns. Questions such as 'Which transport modes are women using?' and 'What are its systematic benefits for climate policy-making?' demand further consideration in current and future scenarios, in light of demographic trends like the increase of elderly in the population. Climate policy-making in urban Norway has a zero growth objective ( $\mathrm{ZGO}$ ) and stipulates that future traffic growth should be absorbed by public transport, walking and cycling. Social differences in travel behaviour along the lines of e.g. gender and age, in the willingness to substitute car and an uneven population growth rate can all pose challenges in achieving climate goals if not addressed through stratified interventions. Considering Oslo's population growth, shifts in age distribution and combining it with empirical evidence on different demographic groups' travel habits, this chapter investigates the overlaps between climate policy-making, gender and ZGO.

In Chapter 12, 'When gender equality and Earth care meet: ecological masculinities in practice', Robin Hedenqvist, Paul M. Pulé, Vidar Vetterfalk and 
Martin Hultman stress that environmental considerations, such as global warming, have traditionally been marginal issues in masculinities research although men are the main perpetrators of the slow violences of social inequalities and ecological destruction. These violences are instigated and maintained by industrial/breadwinner and ecomodern masculinities, which present considerable barriers for men to engage in social and environmental care. The authors suggest ecological masculinities as an alternative for the necessary reconfiguration of masculinities (particularly in the Global North). Interviews from a selected group of men in a progressive community in rural Sweden are used to identify several themes deemed important for a transition from passive awareness to deeper social and ecological actions.

In Chapter 13, 'Diverging priorities for adaptation: towards inclusive wildfire planning in northern Saskatchewan', Heidi Walker, Maureen G. Reed and Amber J. Fletcher explore wildfire management in the province of Saskatchewan, Canada. The region, with one First Nation and two municipal jurisdictions, was among the areas most significantly affected by wildfires in 2015. The chapter examines how institutions for emergency and wildfire management shaped pathways for adaptation, as well as how gender and other intersecting social structures and power influenced these pathways. Drawing from semi-structured interviews with local government representatives and community residents, the authors argue that there is a need for deeper transformative change towards an inclusive wildfire adaptation as the current institutional approaches focus primarily on technical, physical and economic impacts and fail to address many of the more intangible impacts experienced by community residents, many of which were experienced differently across intersections of gender, race, socioeconomic status, and age.

In Chapter 14, which is the final chapter of the book, we reflect on the main findings of the different chapters and the main research questions presented in the introduction.

\section{References}

Alber, G., Cahoon, K. and Röhr, U. (2017) 'Gender and urban climate change policy: Tackling cross-cutting issues towards equitable, sustainable cities', in Buckingham, Susan and Le Masson, Virginie (eds.) Understanding Climate Change through Gender Relations. London and New York: Routledge, pp 64-86.

Allwood, G. (2014) 'Gender mainstreaming and EU climate change policy', The Persistent Invisibility of Gender in EU Policy. European Integration Online Papers, 1(18), pp. 1-26.

Alston, M. (2013) 'Women and adaptation', Wiley Interdisciplinary Reviews: Climate Change, 4(5), pp. 351-358.

Buckingham, S. and Kulcur, R. (2017) 'It's not just the numbers: Challenging masculinist working practices in climate-change decision-making in UK government and environmental non-governmental organizations', in Griffin Cohen, M. (ed.) Climate Change and Gender in Rich Countries. London and New York: Routledge, pp 35-51.

Buckingham, S. and Le Masson, V. (eds.) (2017) Understanding Climate Change through Gender Relations. London and New York: Routledge. 


\section{Kronsell and Magnusdottir}

Bustelo, M., Ferguson, L. and Forest, M. (eds.) (2016) The Politics of Feminist Knowledge Transfer: Gender Training and Gender Expertise. London: Palgrave.

Chaney, P. (2012) 'Critical actors vs. critical mass: The substantive representation of women in the Scottish Parliament', British Journal of Politics and International Relations, 14(3), pp. 441-457.

Chappell, L. and Waylen, G. (2013) 'Gender and the hidden life of institutions', Public Administration, 91(3), pp. 599-615.

Cho, S., Crenshaw, K. and McCall, L. (2013) 'Toward a field of intersectionality studies: Theory, applications, and praxis', Journal of Women in Culture and Society, 38(4), pp. 785-810.

Collins, P.H. (1986) 'Learning from the outsider within: The sociological significance of Black feminist thought', Social Problems, 33(6), pp. 14-32.

Dahlerup, D. (1988) 'From a small to a large minority: Women in Scandinavian Politics', Scandinavian Political Studies, 11(4), pp. 275-97.

Dahlerup, D. (2006) 'The story of the theory of a critical mass', Politics $\mathcal{E}$ Gender, 2(4), pp. 511-522.

Dahelrup, D. and Leyenaar, M. (eds.) (2013) Breaking Male Dominance in Old Democracies. Oxford: Oxford University Press.

Davis, K. (2008) 'Intersectionality as buzzword: A sociology of science perspective on what makes a feminist theory successful', Feminist Theory, 9(1), pp. 67-85.

Djoudi, H., Locatelli, B., Vaast, C., Asher, K., Brockhaus, M. and Sijapati, B.B. (2016) 'Beyond dichotomies: Gender and intersecting inequalities in climate change studies', Ambio, 45(3), pp. 248-262.

Duit, A., Feindt, P.H., Meadowcroft, J. (2016) 'Greening Leviathan: The rise of the environmental state?', Environmental Politics, 25(1), pp. 1-23.

Eisenstein, H. (1996) Inside Agitators: Australian Femocrats and the State. Philadelphia: Temple University Press.

Ergas, C. and York, R. (2012) 'Women's status and carbon dioxide emissions: A quantitative cross-national analysis', Social Science Research, 41(4), pp. 965-976.

Ferguson, L. (2015) 'This Is Our Gender Person', International Feminist Journal of Politics, 17(3), pp. 380-397.

Griffin Cohen, Marjorie. (ed.) (2017) Climate Change and Gender in Rich Countries. London and New York: Routledge.

Hemmati, M. and Röhr, U. (2009) 'Engendering the climate-change negotiations: Experiences, challenges, and steps forward', Gender $\mathscr{E}$ Development, 17(1), pp. 19-32.

Hysing, E. and Olsson, J. (2017) Green Inside Activism for Sustainable Development: Political Agency and Institutional Change. New York: Springer.

IPCC (2014) Climate change: Impacts, adaptation and vulnerability. https://www.ipcc.ch /report/ar5/wg2/ (Accessed 15 November 2020).

Kaijser, A. and Kronsell, A. (2014) 'Climate change through the lens of intersectionality', Environmental Politics, 23(3), pp. 417-433.

Kantola, J. (2010) Gender and the European Union. New York: Palgrave McMillan.

Kenny, M. (2007) 'Gender, institutions and power. A critical review', Politics, 27(2), pp. 91-100.

Kenny, M. (2013) Gender and Political Recruitment: Theorizing Institutional Change. Basingstoke: Palgrave Macmillan.

Kinnvall, C. and Rydstrom, H. (eds.) (2019) Climate Hazards, Disasters, and Gender Ramifications. London and New York: Routledge. 
Kronsell, A. (2016) 'Sexed bodies and military institutions: Gender path dependency in EU's common security and defense policy', Men and Masculinities, 19(3), pp. 311-336.

Krook, M.L. and Mackay, F. (eds.) (2011) Gender, Politics and Institutions. Towards a Feminist Institutionalism. New York: Springer.

Ljungholm, D.P. (2017) 'Feminist institutionalism revisited: The gendered features of the norms, rules and routines operating within institutions', Journal of Research in Gender Studies, 1(7), pp.248-254.

Lovenduski, J. (2005) State Feminism and Political Representation. Cambridge: Cambridge University Press.

Lowndes, V. (2020) 'How are political institutions gendered?', Political Studies, 68(3), pp. $543-564$.

Lykke, N. (2010) Feminist Studies: A Guide to Intersectional Theory, Methodology and Writing. London and New York: Routledge.

MacGregor, S. (ed.) (2017) Routledge Handbook of Gender and Environment. London and New York: Routledge.

Mackay, F., Kenny, M., and Chappell, L. (2010) New institutionalism through a gender lens. Towards a feminist institutionalism?', International Political Science Review, 31(5), pp. 573-588.

Magnusdottir, G.L. and Kronsell, A. (2015) 'The In(visibility) of gender in Scandinavian climate policy-making', International Feminist Journal of Politics, 17(2), pp. 308-326.

Magnusdottir, G.L. and Kronsell, A. (2016) 'The double democratic deficit in climate policy-making by the EU Commission', Femina Politica: Zeitschrift für feministische Politikwissenschaft, 25(2), pp. 64-77.

March, J.G. and Olsen, J.P. (1989) Rediscovering Institutions: The Organizational Basis of Politics. New York: Free Press.

Miller, C. (2020) 'Parliamentary ethnography and feminist institutionalism: Gendering institutions-but how?', European Journal of Politics and Gender.

Mushaben, J.M. (2012) 'Women on the move. EU migration and citizenship policy', in Abels, G. and Mushaben, J.M. (eds.) Gendering the European Union: New Approaches to Old Democratic Deficits. Houndsmill, Basingstoke: Palgrave MacMillan, pp. 208-227.

Nagel, J. (2012) 'Intersecting identities and global climate change', Identities-Global Studies in Culture and Power, 19(4), pp. 467-476.

Pierson, P. (2004) Politics in Time. History, Institutions, and Social Analysis. Princeton, NJ: Princeton University Press.

Phillips, A. (1995) Politics of Presence. Oxford: Oxford University Press.

Resurrección, B. (2013) 'Persistent women and environment linkages in climate change and sustainable development agendas', Women's Studies International Forum, 40, pp. $33-43$.

Skutsch, M.M. (2000) 'Protocols, treaties, and action: The 'climate change process' viewed through gender spectacles', Gender $\&$ Development, 10(2), pp. 30-39.

Sommerer, T. and Lim, S. (2016) 'The environmental state as a model for the world? An analysis of policy repertoires in 37 countries', Environmental Politics, 25(1), pp. 92-115.

Tobin, P. (2017) 'Leaders and laggards: Climate policy ambition in developed states', Global Environmental Politics, 17(4), pp. 28-47.

UNFCCC (2015) United Nations framework convention on climate change, The Paris Agreement. https://unfccc.int/process-and-meetings/the-paris-agreement/the-parisagreement (Accessed: 22 November 2019).

Yeatman, A. (2020) Bureaucrats, Technocrats, Femocrats: Essays on the Contemporary Australian State. London and New York: Routledge. 


\section{Kronsell and Magnusdottir}

Wängnerud, L. (2009) 'Women in parliaments: Descriptive and substantive representation', Annual Review of Political Science, 12, pp. 51-69.

Waylen, G. (2014) 'Informal institutions, institutional change, and gender equality', Political Research Quarterly, 67(1), pp. 212-223.

Woodward, A. (2003) 'European gender mainstreaming. Promises and pitfalls of transformative policy', Review of Policy Research, 20, pp. 65-88. 